\title{
Lisbon's Establishment-based Freight Survey: revealing retail establishments' characteristics, goods ordering and delivery processes
}

\author{
André Romano Alho ${ }^{1}$ João de Abreu e Silva ${ }^{1}$
}

Received: 7 November 2014 / Accepted: 26 March 2015 / Published online: 23 April 2015

(C) The Author(s) 2015. This article is published with open access at SpringerLink.com

\begin{abstract}
Introduction Establishment-based freight surveys (EBFS) are a specific data collection process for urban freight operations. The focus of both this research, and of the data collection process, was to investigate vehicle activity at urban retail establishments. This work reports on the formulation, development, application and statistical analysis of an EBFS with a sample of 604 establishments in Lisbon, Portugal. It contributes towards the systematization of the available knowledge and aims to potentially support the process of developing future EBFS as well as to inform researchers and policy-makers of establishments characteristics and delivery patterns.

Methods Several statistical analyses were performed to the survey answers' distributions such as Spearman correlations, line / scatter plots and Ordinary Least Squares (OLS) linear regressions.

Results New insights into variables' worth are provided, such as the influence of industry category on the vehicle arrivals throughout the day or the influence of the number of employees on the total of weekly deliveries. It is revealed that modeling freight trip generation might be prone to considerable errors, which has implications if EBFS data is to be used in simulation models to test policy alternatives.

Conclusions It is concluded that stricter parking policies should be in place to avoid obstruction-causing parking practices. Also, the results support advising further research in the
\end{abstract}

André Romano Alho

andre.alho@tecnico.ulisboa.pt

João de Abreu e Silva

joao.abreu.silva@tecnico.ulisboa.pt

1 CESUR/DECIVIL, Instituto Superior Técnico, Universidade de Lisboa, Av. Rovisco Pais, 1049-001 Lisboa, Portugal field of load consolidation and on the effect of the ordering process in the total trips generated by a retail establishment.

Keywords Establishment-based freight survey · Urban freight - City logistics · Data collection · Case study . Loading-unloading operations

\section{Introduction}

Using an Establishment-based Freight Survey (EBFS) implemented in Lisbon, Portugal, as a departure point, we review this specific method of urban freight operations data collection. Reporting on conducted EBFS is not novel. However, this paper contributes to current knowledge by providing: a) a review of existing literature related to EBFS, aiming to systematize the available knowledge; b) a detailed description of the Lisbon EBFS development and implementation choices to potentially support the process of developing future similar surveys; and c) the analysis of statistical indicators regarding the retail establishments' characteristics and delivery patterns, which can be useful to inform future research and policy making.

Allen and Browne [1] summarized the main aspects of urban freight transport that have been subject to data collection via surveys. EBFS are the main method to collect data about freight vehicle trips to and from establishments, in an urban context. These surveys are also the most adequate sources of information to predict logistics behavior/traffic flow of urban freight and relate it with urban land use patterns. It is claimed that, although expensive, the accuracy of its estimates is generally very good [2]. Due to the EBFS capability for informing the predictions of urban freight movement generation, EBFS data is suitable for use in simulation models applied in urban planning or city logistics policymaking. For 
these reasons, EBFS are relatively popular, especially in Europe, and a small subset ( $\sim 96$ EBFS) mentioned in [1] is shown in Fig. 1.

Despite the usefulness of EBFS within the realms of urban freight analysis and modeling, there are no standards regarding their: structure/content; sampling methodology or survey implementation process. Allen and Browne [1] hypothesize two main reasons for the nonexistence of standards: many study reports are not publicly available and the procurement of the available ones is difficult and time consuming. In addition, despite many similarities, the intent of these surveys might be widely variable and the influence of local context might not be negligible as each survey can be highly tailored to serve the researchers' purposes.

This article is structured as follows. The following section, Literature Review, presents and discusses the available knowledge over various dimensions of EBFS (e.g., structure, content, sampling, implementation guidelines). The Research Methodology contains a description of objectives, justification over the selected sampling technique/case-study zones, and details of the survey content. The Results and Discussion section summarizes the most relevant survey analysis results and hypotheses which could be derived from them, namely establishments' characteristics, weekly deliveries by period of time and establishment category, relevant correlations and the influence of establishment size on weekly deliveries/items received. Finally, we provide general conclusions regarding the implications of the findings for future research and informing policy-making.

\section{Literature review}

\subsection{Survey structure and content definition}

The data needs for the study of urban freight transport were defined by Ogden [3] as dependent on:

- The issue of concern;

- The planning and policy framework in which the issue arises;

- Established practice in data collection;

- The availability of previously collected data.

In addition, Routier and Toilier [4] propose three basic requirements for the definition of a data collection process. These are: coherence, relevance and measurability. It is claimed that the efficiency of the chosen methodology relies on the balance between these three attributes. The perfect alignment between the objectives of the data collection process and survey structure/content is a reflection of its coherence and relevance. Measurability is implicitly assumed in the questionnaire design. Consequently, we consider the factors defined in Ogden [3], as determinants of the structure/content.

Due to ambiguities in the definition of urban freight transport (e.g., broad as in [5] or restricted in space as in [6]) there is a need to define precisely urban freight dimensions that are to be captured with the EBFS. In other words, the description of freight movements that ought to be captured by the survey should be defined a-priori. Allen et al. [5] have defined urban freight comprising the following categories of movements:

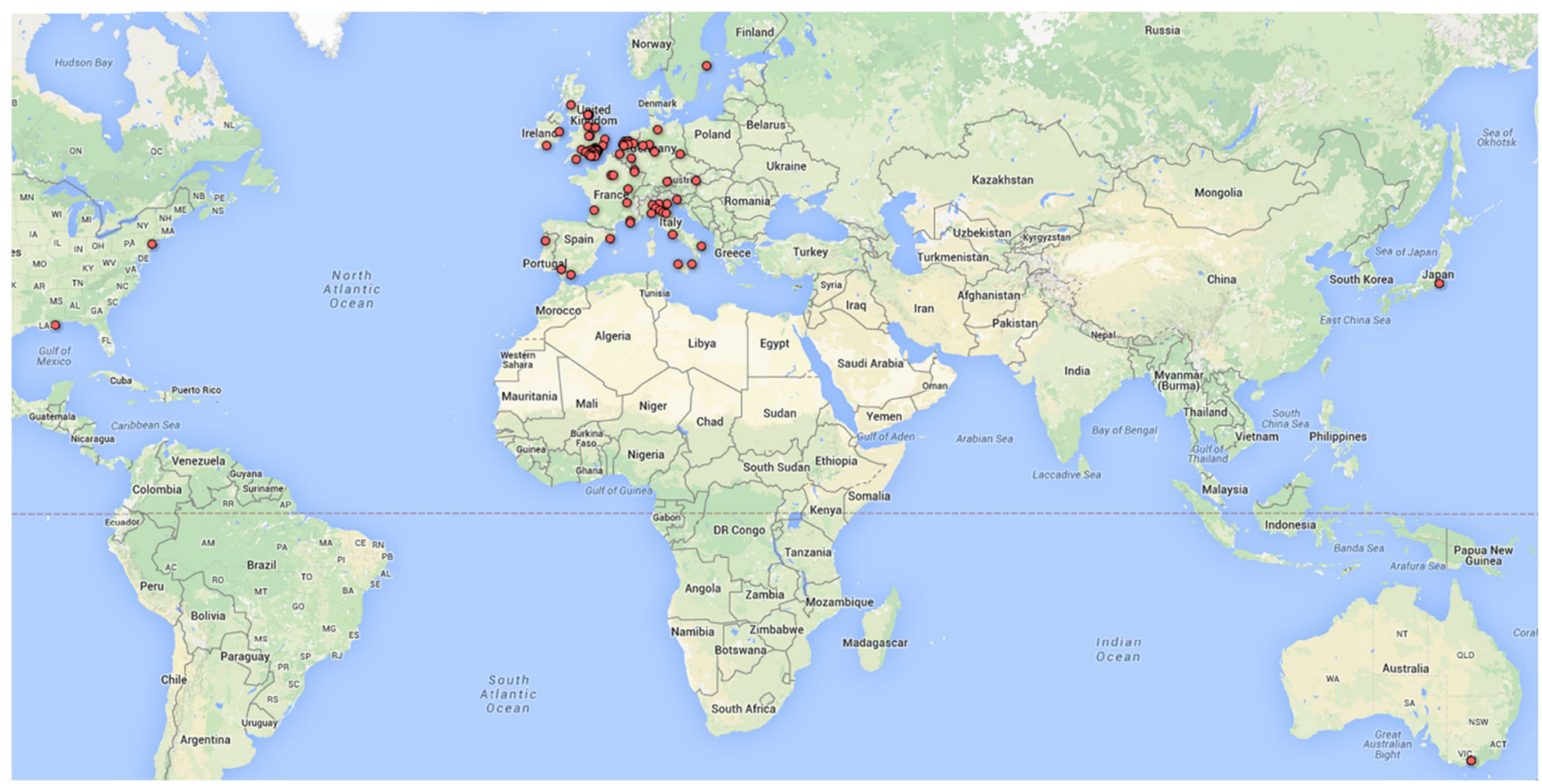

Fig. 1 Plotted record of some locations where EBFS were implemented, based on [1] (map courtesy of Google Maps) 
collections, deliveries and transfers (e.g., goods, money, waste), service activities (e.g., equipment installation trips), and other commercial purposes (e.g., sales representatives), inclusive of all types and sizes of goods vehicles.

While it is possible to define general purposes for EBFS data collection, the selected questions are dependent on the research objectives. This can be confirmed by comparing the structure/content of various surveys presented by Allen and Browne [7]. Another example of the questions presented to shopkeepers can be found in Debauche [8]. It is commonly acknowledged that it is equally important to consider the delivery/collection of goods, as well as the service provision generating vehicle activity [5, 9]. Holguín-Veras and Patil [10] add that empty trips must also be considered. Still, EBFS have been deployed and used successfully without both of these components [11].

\subsection{Sampling}

There are two main EBFS widely detailed in the literature. For those used as the basis for the Calgary/Edmonton tour-based freight vehicle model, an alignment between the total employment by industry category in the case study area and in the region was achieved [9]. This allowed sampling until a prespecified number of complete surveys was obtained for each industry category, an example of the stratified sampling methodology.

The surveys preceding the FRETURB freight model targeted all establishments except public services such as schools or local authorities [2]. A stratified sampling method was used, and it was based on industry category, number of employees and a comprehensive geographical coverage of the conurbation. It is claimed that a stratified sample and poststratification improve noticeably the accuracy of the coefficients (for the generation of deliveries and pick-ups). Still, no indications on the dimension of such improvement, or on the post-stratification process, are detailed.

\subsection{Guidelines to survey implementation}

According to the compilation of studies in Allen and Browne [1], the number of respondents for EBFS (sample of $61 \mathrm{EBFS}$ ) varied significantly (average of 456 and standard deviation of 666). EBFS are commonly conducted via interviews, which can be performed over the telephone, by face-to-face interaction, or by self-completion. Telephone calls and face-to-face interaction are commonly used to obtain prior permissions and make other survey related arrangements. The authors have also provided an analysis over the advantages and disadvantages of these methods. The response rate varied according to surveying method:
- Self-completion (sample of 19): average response rate of $25 \%$, standard deviation of $16.5 \%$.

- Interview (phone-based or face-to-face, sample of 11): average response rate of $59 \%$, standard deviation of $22.3 \%$.

- All (sample of 35): average response rate of $38 \%$, standard deviation of $24.7 \%$.

Albeit being more expensive and time consuming, the mixed approach on the Calgary/Edmonton EBFS is the most complete, including an introductory e-mail, a follow-up telephone call, a formal recruitment letter/fax and a final telephone call [9]. The EBFS used by the FRETURB model started with two different approaches: sending a questionnaire to establishments and Computer Assisted Telephone Interviews [12]. Eventually, the Computer Assisted Telephone Interviews were replaced by a phone call and a postal questionnaire. Numerous phone calls were needed to clarify specific issues in the surveys. The authors conclude that, although more expensive, the face-to-face method is the most efficient technique.

The FRETURB model EBFS were performed in an ordinary week, from Monday to Sunday [2]. It is claimed that it is impossible to calibrate data from only 1 day without knowing the weight of this day in the total week. Collecting information on seasonal changes (weekly or monthly) is recommended. This is important due to the difficulty of carrying out these surveys in a periodic way, not only due to its high costs, but also to the lack of involvement by stakeholders and funding authorities [12].

These major surveys requested establishments to fill a log of the deliveries/collections for a period of, respectively, 1 day or 1 week $[9,12]$. This enabled the researchers to know, for example, the precise arrival and departure time of vehicles as well as vehicle type and product quantities delivered.

\subsection{Extrapolation of freight delivery details}

Some questions within EBFS aim to capture, as accurately and precisely as possible, the freight delivery details for a sample of establishments during a specific period (e.g., total deliveries per establishment per day). A common goal of collected freight delivery details is to allow expanding the sample characteristics to the population. This can be achieved, for example, using mathematical models relating the variation of the observed freight trip generation against the variation of a set of variables. More details about freight trip generation modeling can be found in Alho and de Abreu e Silva [13, 14]. Freight delivery characteristics, such as the urgency of deliveries can be generalized from the sample to the population by assigning probabilistically a specific answer (e.g., non-urgent) based on the sample distribution, even with some level of 
stratification (e.g., by industry category) as in Alho and de Abreu e Silva [15].

Danielis et al. [16] propose a set of minimum features that should be used to characterize the complexity of transport and logistics activities, in distribution channels. These features are based on the analysis structure put forward by Allen et al. [17]. EBFS alone are not enough to fulfill these minimum features. In order to obtain detailed information about vehicle trips, EBFS should be complemented with other surveys [2], allowing indepth knowledge over the full supply chain. An observation process, including vehicle counts and recording of activity details such as dwell time, is commonly used to confirm/calibrate the predicted delivery patterns arising from EBFS $[11,18,19]$. EBFS plus the "vehicle observation" process can then be the most efficient and cost-effective methods for understanding a wide range of issues, associated with urban freight deliveries/ collections, from the perspective of establishments [1].

However, there is a particular freight delivery detail that must be addressed within the context of EBFS development: the estimation of dwell time (i.e., deliveries' duration). There is an extensive list of influences on the freight vehicle dwell times $[5,17]$, which highlights the complexity in predicting/ extrapolating dwell times. Research revealed a weak correlation between establishment size and the mean dwell time of core goods delivery vehicles [20]. "Core" goods are those of fundamental importance to the activity carried out at the establishment. The challenge of identifying the type of goods carried by freight vehicles, during the observation process, has been stated by Comendador et al. [21]. As estimates from establishment surveys are usually over- or under-estimated, when compared with observations from tour-based surveys, Allen et al. [17] proposed asking for dwell time estimates according to vehicle type, as a way to increase precision, even though estimates' accuracy can still be questionable.

Melo [22] inspected zones, blocks and streets with mobility problems, and high pressure of freight vehicles, during freight traffic peak periods. Freight activity was observed in their surroundings. This data collection process recorded, among others, the parking time and duration, the frequency of deliveries per branch of activity and the type of freight vehicle. Debauche [8] also reported an observation process of delivery behavior. Similar details to those presented in Melo [22] were recorded for every vehicle movement, plus information about the obstructions caused, if any.

\section{Research methodology}

Lisbon's EBFS was designed according to seven key points, arising from the literature review:

- The issue: the survey was developed to allow the extrapolation of daily deliveries per time period, for each establishment, reflecting freight parking demand. Establishments were defined as retail establishments, a physically delimited private operation where commodities are sold to the public in relatively small quantities for use or consumption rather than for resale.

- Planning and policy framework: there was no government-related planning or policy framework backing this survey. Albeit its aims and framework were purely research related, freight parking demand is a pressing planning issue and EBFS allow understanding urban freight movements in a way that can facilitate the definition of policies or plan to better accommodate parking demand.

- Established practice in data collection: as far as the authors can attest, this is the first survey of this kind (and scope) made in Portugal. In Portugal, there is no established practice in urban freight data collection.

- Availability of previously collected data: there is no previously collected data minimally aligned with what was collected by the survey. Out of a comprehensive list of general data gaps in Browne and Allen [23], the following were the target of the proposed survey:

- Data about light goods vehicle activity;

- Data about urban freight and logistics infrastructure;

- Data about loading and unloading operations and infrastructure for goods vehicles;

- Geographical data about goods vehicle trips in the urban areas.

- Objectives of the data collection process: the main objective of this survey was to allow estimating the total number and patterns of deliveries for retail establishments present in the study area. Such data will be used to build models of freight vehicles parking demand. In addition, the survey should allow exploring the relevance of several freight trip generation predictor variables worth for retail system characterization. For that the EBFS serves the purpose of collecting information about the freight vehicles visiting an establishment (e.g., to unload goods), the characteristics of the establishment and of the goods ordering process.

- Definition of urban freight transport: only within an urban/ metropolitan context, in accordance with the definition presented in Allen et al. [5].

- Description of movements to be captured: the focus of this data collection process will be the vehicle activity to and $a t$ urban retail establishments, excluding vehicle activity departing from establishments. It is defined as any activity that involves loading/unloading operations to retail establishments. 
It must be noted that retail establishments are not the sole generators of freight trips. In fact, the share of freight deliveries to non-retail (e.g., services establishments, offices, small manufacturing) activities is largely unknown, and in some cases with offices being reported as a considerable generator of freight movement [5]. This study assumed that they represent a considerable share that justifies a specific study. Furthermore, it also leveraged heavily on the existence of a retail establishment database that allowed an accurate process of sampling that is certainly representative of the retail population. This would not have been possible if considering offices, for example, as no detailed record exists of the offices' location or dimension.

For the present study, the geographical and goods establishments' coverage is in line with the majority of urban freight data studies: it covers a sample of establishments across Lisbon city center, and includes a wide range of establishments. The case study area was within the Parking Authority/Municipal Mobility Company (EMEL) operating area, highlighted in Fig. 2. These areas were selected because they were assumed to have the worse traffic problems generated by inappropriate freight parking practices. Also, for these zones there is data available about the location and quantity of loading/unloading bays, as well as data relative to on-street parking demand and supply. These are all important factors as the survey aimed to collect data that allows predicting freight trips generated by retail establishments. These freight trips will be assumed equal to the parking demand required by freight vehicles nearby each establishment, and used to simulate the impact of parking and parking enforcement on reducing double parking by freight vehicles [24]. It should be highlighted that the sum of delivery trips received by a group of retail establishments is likely bigger than the sum of freight vehicles visiting those establishments; freight vehicles often perform trip chains (tours) in which several retail establishments are served.

Regarding sample size, our calculations were based on the aggregated results from the latest Lisbon "Retail Commerce, Food and Beverages Census" [25]. As only aggregated results (per civil parish, ${ }^{1}$ a municipality subdivision) were available, a non-official goods establishment database was also used [26]. The latter is similar to the Census data although somewhat dated and based on estimates for establishment location, size and number of employees. Within the case study area, the total number of establishments was assumed to be 11, 424.

Just as in the major EBFS that have in common some variation of the stratified sampling methodology, we attempted to explore the three elements of the stratification

\footnotetext{
${ }^{1}$ Civil parish is the English name for Freguesia, an administrative subdivision within the Portuguese municipalities. It is called civil parish to differentiate it from a catholic parish from where they were derived.
}

process present in Ambrosini et al. [2]: category, size and location of establishments. Establishment "size" was not considered in the stratification process due to the lack of data regarding disaggregated establishment area, as suggested in Cherrett et al. [20], or number of employees, as suggested in Lawson et al. [27]. Regardless, the aim was to survey retail establishments with less than $500 \mathrm{~m}^{2}$. Consequently, the stratification considered:

- Category of establishments: City Council establishment industry classifications - categories - were adopted (10 categories). The share of each category was calculated for a selected group of zones that overlapped the casestudy area. This was considered a reasonable assumption as the total number of establishments in the zones (Census-based) was similar to the total number of establishments in the non-official database.

- Land-use clusters: six clusters of zones, arising from previous analyses (Fig. 2), were selected due to hypothesized significant differences in land-use (e.g., residents density, shops density). The shape of the zones is defined by Lisbon's parking authority managerial discretion. As clusters were selected using land-use variables, geographical continuity is not mandatory and neither is homogeneity of cluster size (number of member zones). Land-use variables such as numbers of buildings, dwellings and residents were obtained from the last Census [28]. All variables represent the average for each cluster of zones. Average speed loss was calculated subtracting the average speed on links from the average maximum speed from $8 \mathrm{AM}$ to $12 \mathrm{PM}$ using aggregate estimates for all types of vehicles. Retail establishments locations were obtained from [26] and the retail heterogeneity indicator calculated as detailed in [15].

According to the sample size calculator by Raosoft [29], the minimum sample size is equal to 372 (margin of error: $5 \%$; confidence level: $95 \%$; response distribution for the highest sample size: $50 \%$ ). The number of sampled establishments per cluster was first calculated proportionally to the percentage of establishments in that cluster. Then, the split among industry categories, within each cluster, was calculated according to the overall proportion of establishments for each industry category in the case study. The proportion of industry categories is illustrated in the rightmost column of Table 1. Sample stratification and spatial distribution are detailed on Table 1. Table 2 presents the land-use characteristics of the clusters.

Survey implementation was attempted as an internetbased survey with dissemination through the commerce/ trade associations of Lisbon. This was a largely unsuccessful effort in what concerns the total response $(n=10$ in 2 months), which we assumed as derived from the 
Fig. 2 Lisbon city boundaries, EMEL operating area (outlined in blue) and surveyed zones (lettered)

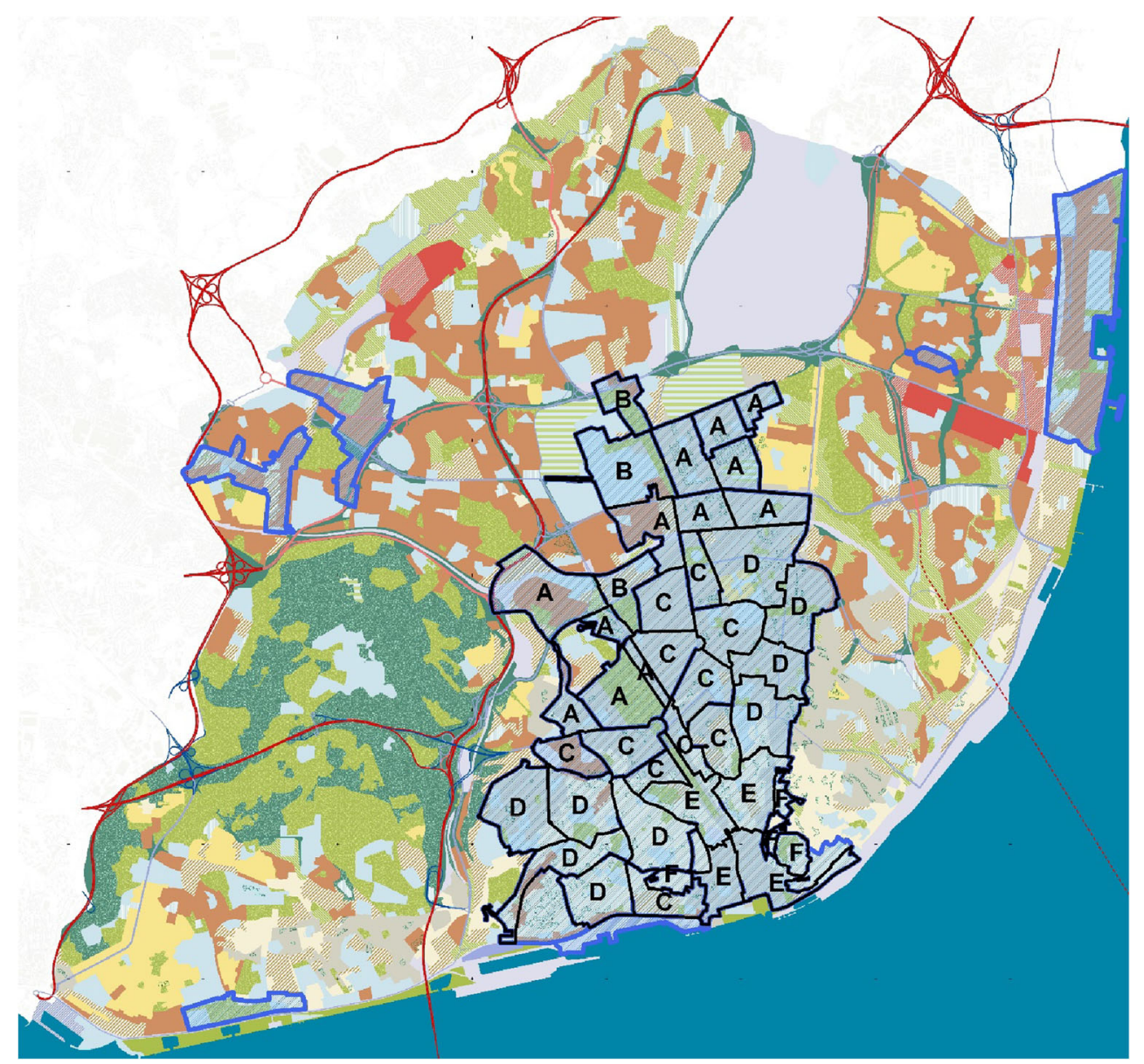

weak dissemination potential of mailing lists from the commerce/trade associations. This led to a change of methodology to face-to-face interviews.

Contrary to the experience in the major surveys, the establishments' support to this type of study was very limited, and the research conditions only allowed a single contact opportunity with establishments. A company with expertise in traffic surveys was hired to implement the interviews. The company employees were specifically trained to conduct the survey according to the desired quality standards and tested it with a pilot of 10 interviews. Surveys forms were filled digitally using small-form laptops (netbooks) during the interview.

Table 1 Sample stratification (no. of respondents)

\begin{tabular}{|c|c|c|c|c|c|c|c|c|}
\hline Sampling zones & A & $\mathrm{B}$ & $\mathrm{C}$ & $\mathrm{D}$ & $\mathrm{E}$ & $\mathrm{F}$ & Sum & $\%$ of total \\
\hline Category 1 - Specialized foodstuffs & 5 & 0 & 9 & 10 & 7 & 0 & 31 & $5 \%$ \\
\hline Category 2 - Non-specialized foodstuffs & 4 & 0 & 7 & 8 & 6 & 0 & 25 & $4 \%$ \\
\hline Category 3 - Personal usage articles & 16 & 2 & 27 & 33 & 24 & 2 & 104 & $17 \%$ \\
\hline Category 4 -Culture and leisure & 9 & 1 & 15 & 19 & 14 & 1 & 59 & $10 \%$ \\
\hline Category 5 - Various & 12 & 1 & 22 & 23 & 18 & 1 & 77 & $13 \%$ \\
\hline Category 6 - Home appliances & 8 & 1 & 14 & 16 & 12 & 1 & 52 & $9 \%$ \\
\hline Category 7 - Non-specialized & 2 & 0 & 3 & 4 & 3 & 0 & 11 & $2 \%$ \\
\hline Category 8 - Health and hygiene & 4 & 0 & 8 & 8 & 6 & 0 & 26 & $4 \%$ \\
\hline Category 9 - Repairs & 4 & 0 & 7 & 8 & 6 & 0 & 25 & $4 \%$ \\
\hline Category 10 - Food and drinks & 30 & 3 & 50 & 62 & 45 & 3 & 193 & $32 \%$ \\
\hline$\%$ of total & $16 \%$ & $1 \%$ & $27 \%$ & $32 \%$ & $23 \%$ & $1 \%$ & - & - \\
\hline
\end{tabular}

“_” means "not applicable” 
Table 2 Clusters' land-use

\begin{tabular}{|c|c|c|c|c|c|c|}
\hline \multirow[t]{2}{*}{ Variable } & \multicolumn{6}{|l|}{ Cluster } \\
\hline & A & B & $\mathrm{C}$ & $\mathrm{D}$ & $\mathrm{E}$ & $\mathrm{F}$ \\
\hline Buildings $\left(\mathrm{Km}^{2}\right)$ & 871 & 264 & 1262 & 2074 & 1674 & 4759 \\
\hline Dwellings $\left(\mathrm{Km}^{2}\right)$ & 7132 & 2170 & 8102 & 12,289 & 7948 & 22,565 \\
\hline Dwellings / Building & 8 & 8 & 6 & 6 & 5 & 5 \\
\hline Residents $\left(\mathrm{Km}^{2}\right)$ & 11,328 & 3592 & 11,984 & 18,606 & 9659 & 30,857 \\
\hline Average Speed Loss $(\mathrm{Km} / \mathrm{h})^{\mathrm{a}}$ & 17 & 16 & 22 & 21 & 19 & 25 \\
\hline Retail Establishments $\left(\mathrm{Km}^{2}\right)$ & 370 & 62 & 728 & 643 & 1198 & 616 \\
\hline Retail Heterogeneity $^{\mathrm{b}}$ & 0.80 & 0.61 & 0.78 & 0.81 & 0.79 & 0.67 \\
\hline
\end{tabular}

${ }^{a}$ Congestion derived speed loss versus maximum allowed. For morning peak period (7 AM to 9 AM)

${ }^{\mathrm{b}}$ Varying from 0 to 1 , where 0 means completely homogeneous (i.e.,: only one category of establishments). Based on 135 classes of establishments

The survey forms were hosted online in SurveyMonkey (www.surveymonkey.com) making the results accessible in real-time. Establishments were not contacted a-priori and no records were kept over the total of establishments contacted, as the interviewers approached establishments randomly and asked for the staff member who was more knowledgeable about the delivery details for that establishment. If the interviewee accepted to answer, the survey process would start. Otherwise, they would keep on looking for another establishment. 642 forms were filled, out of which 604 were complete and had consistent answers. The survey was conducted between March and June 2013. The reported results are based on the 604 complete surveys.

Various publications list indicators that can be used in the context of post-survey analysis $[1,8,12,20]$. Based on the literature, a set of indicators was defined during the survey development process, targeting postsurvey analysis. The final selection of indicators also had an influence on the survey structure and selection of questions. Our EBFS is considered one of the most comprehensive, when compared with the forms listed in [7]. Hence, due to its length, the summarized structure is presented as:

- Characteristics of the establishment (e.g., location, category, area, employees, fleet) and of the contact person (e.g., name, job, e-mail);

- General characteristics of loading/unloading operations (e.g., urgency of deliveries, ordering process, supply chain details);

- Specific characteristics of loading/unloading operations (e.g., deliveries per daily time period, seasonal changes);

- Characteristics of the core loaded/unloaded goods (e.g., volume, weight, perishability, fragility, requires refrigeration);
- Perception/opinion about the loading/unloading operations.

As the location of public loading/unloading bays was available, no question is dedicated to the available parking for loading/unloading operations in the surroundings. The exception is due for the existence of private loading/unloading bays for which a question was included in the survey.

As the research conditions only allowed a single contact opportunity with establishments, respondents were asked to answer the some questions under the format of categorized intervals (e.g., area between $x \mathrm{~m}^{2}$ and $y \mathrm{~m}^{2}$,):

- Establishment and warehouse area;

- Types of deliveries (answer in \% of e.g.,: core goods, services, mail and express deliveries);

- $\%$ of deliveries by element in the supply chain (e.g.,: ownaccount, $3^{\text {rd }}$ Party Logistics $-3 \mathrm{PL}$ );

- Total deliveries per daily time period (within a time frame of $2 \mathrm{~h}$ intervals);

- Type of vehicle delivering (number of weekly deliveries and most frequent duration of the delivery);

- Parking location (frequency and distance according to type, e.g.,: loading/unloading bay, lane);

- Amount of commodities received weekly (type and volume).

In the results section we present the more relevant findings of the statistical analysis of single and aggregated responses. For that, several statistical analyses were performed such as Spearman correlations (as some variables are not normally distributed), line / scatter plots and Ordinary Least Squares (OLS) linear regressions. The explored topics are:

- Total (weekly) deliveries;

- Establishment size (represented by establishment sales area, warehouse area, establishment "shop front" width, total number of employees, total number of suppliers); 
- Duration of deliveries (the declared most frequent delivery duration for the most frequent vehicle type/size visiting the establishment);

- Commodities' characteristics (weight, volume, perishability, fragility, special requirements such as refrigeration);

- Quantity of commodities (it was assumed that, independently of commodity volume, every item would be considered as a single item. i.e., bag, box or crate, regardless of size, would count as one item);

- Supply chain characteristics:

- Urgency of deliveries;

- Interval between orders;

- Order arrival time;

- Delivery routine (i.e., day and time of deliveries as well as choice of supplier which could be Defined, Non-defined, Mixed);

- Delivery entity (own-account; 3PL, producer, wholesaler, mixed, other);

- Delivery planner (own-account; 3PL, producer, wholesaler, other);

- Stock management (visual, computer-based, external, other);

- Distribution chain (decentralized, centralized, hybrid, other);

- Type of delivery (between chain establishments, between unrelated establishments, single trip, mixed);

- Origin of the delivery (company warehouse, wholesaler warehouse, producer, other).

For the OLS linear regressions, the data were subject to an outliers and influential records removal process. The process was based on a linear regression model with total deliveries per week as the dependent variable and total employees as the independent variable. Outliers were identified using the studentized residuals, leverage of the predictor variable values searching for extreme values, and influential records were identified using Cook's D, DFITs and DFBETA. For that, a series of tests was performed as detailed in UCLA [30]. The joint outcome of these tests revealed 45 records $(7 \%)$ that were eliminated. This process allowed obtaining stronger correlations, lower errors and higher $\mathrm{r}^{2}$ statistics and was consequently considered appropriate.

\section{Results and discussion}

\subsection{Overall perspective of retail establishments' characteristics}

Providing an overall perspective of the retail establishments' characteristics allows a better understanding of the case study but also provides some ground for comparison between research case studies. The presented information is, when a reference was found, matched with previous research results, otherwise it is novel to the best of our knowledge.

Eighty-two percent of surveyed establishments are independent (i.e., not part of a co-op, association or retail chain) and their size is generally small, $79 \%$ are smaller than 100 square meters. Also, $40 \%$ have no dedicated storage area. The typical establishment has 3 employees, 1 of them is usually the business proprietary. Despite the majority of establishments being small, the fact that they are independent might point towards considerable freight trip generation as pointed in Cherrett et al. [20], which might require the need for a dedicated sustainable freight mobility plan.

Sixty-eight percent of establishments do not own any vehicles and $27 \%$ have one vehicle. Ninety-nine percent of those who have a vehicle own a "light" vehicle (Gross Weight $<3.5 \mathrm{~T}$ ) which can be the owners' vehicle that is used personally and professionally. Only $14 \%$ of establishments have parking permits for their vehicles, a hint that most of them can probably occupy the loading/unloading bays for the duration of the working hours. This highlights the pressing issue of limiting parking duration in loading/unloading bays, to assure availability of the infrastructure.

Regarding the relative importance of delivery types, typically core goods represent $90 \%$ of the deliveries, with ancillary goods and postal collection/deliveries representing $5 \%$ each. Hence, core goods deliveries' characteristics can be assumed as predominant for each establishment. Sixty percent of total deliveries are performed by a 3PL (third party logistics), $15 \%$ by company owned vehicles and $15 \%$ by the wholesaler. Seventy-six percent of establishments considered their delivery routine as non-defined, meaning it varies according to need. This is a very strong argument against the value of using statistical models to predict establishment deliveries in a certain time period (e.g., hour, day). Whilst the model output might be a good fit for the sample, it is known apriori that the sample cannot represent reality accurately as it is too dynamic to be captured within a week of sampling.

Considering the tolerance to delays in deliveries, three levels were defined: Urgent - in which deliveries had to be performed at precise time intervals, Relevant - when small delays were acceptable and Irrelevant - when delays do not affect establishment operations. Forty-eight percent of establishments considered their deliveries to have a Relevant character, $12 \%$ were classified as Urgent and the remaining, Irrelevant. The majority of urgent deliveries (58\%) was associated with "Food and drinks" establishments (e.g., restaurants), second was the category "Various" $(15 \%)$. This was expected as most restaurants receive bread, cheese, fish and meat daily. Interestingly, $69 \%$ percent of Pharmacies $(n=16)$ stated that delays were irrelevant. We hypothesize that one of the reasons for this is the higher than average number of weekly deliveries (17 vs. 9 for the full sample). 
Fifty-seven percent of the establishments perform visual inspections to assess stock levels. Which might be associated with less-than-optimal ordering processes that generate a higher number of deliveries. The delivery day/time was defined for $67 \%$ of the cases by the 3PL company, $24 \%$ by the establishment and $7 \%$ by the wholesaler. After ordering, $65 \%$ receive their goods the following day. Eighty-nine percent of the orders always arrive from various shipping points, $10 \%$ always from a single shipping point and $1 \%$ from a mixed system (sometimes multiple points, sometimes one). Multiple shipping points might, or not, be associated with different suppliers. Core goods depart from the wholesaler warehouse in $47 \%$ of the cases, from the producer $43 \%$ and from the company warehouse $10 \%$. The number of reported suppliers varied significantly:

- Up to 5: 32\%

- Between 5 and 10: 35\%

- From 10 to 25 : $\sim 24 \%$

- Over 25: 10\%

Only $6 \%$ of establishments reported their deliveries as always arising from single trips, which highlights the tour nature of urban freight deliveries. Furthermore, this might be associated with the high percentage of deliveries by 3PLs and wholesalers. Practically, this can inform that while freight trip models can predict the number of freight vehicles visiting the establishment, the total of vehicles circulating could be considerably smaller, as each vehicle will likely make several stops.

Thirty percent of establishments report that vehicles never perform loading operations. Ninety-one percent of the establishments do not accept loading/unloading operations off public operation hours, which might pose an obstacle to the implementation of off-hour delivery policies if there is no incentive to change [31]. Ninetyfour percent of establishments inspect the deliveries upon arrival, although it is not known if the delivery driver waits whilst this check is performed. If so, this would increase the delivery time.

Light goods vehicles (Gross Weight $<3.5 \mathrm{~T}$ ) deliveries were reported to generally take up to $5 \mathrm{~min}$ in $69 \%$ of the cases and between 5 and $15 \mathrm{~min}$ in $26 \%$. For small trucks $(3.5 \mathrm{~T}<$ Gross Weight $<7.5 \mathrm{~T})$ the figures are, respectively, 53 and $30 \%$, and hence are slightly more prone to stay parked for a longer period of time, but not necessarily associated with more delivered items.

Seventy-nine percent of establishments said that no month had a comparatively higher number of deliveries. For those reporting increases, $77 \%$ said that the number of deliveries could be up to $50 \%$ higher than average per month. March, September, October and December were the months when most deliveries were received. Seventy-eight percent of establishments reported that no month had a significant decrease in number of deliveries. For the remaining, January and August were the months with fewest deliveries. Eighty-nine percent of these stated that the reduction was below $50 \%$ the average number of deliveries per month. It can be hypothesized that there is considerable alignment between the discount sales periods and the reported changes in deliveries. The increase in deliveries occurs between the summer sales (July 15 to September 15) and winter sales (December 28 to January 28) except for March which can be assumed as the stock-up period for summer. The decrease overlapped with the sales periods (January and August). Still, it can also be generalized that the majority of establishments do not suffer from significant seasonal changes in deliveries and that the selection of the sampling period did not affect considerably the results.

Regarding parking location, $54 \%$ of establishment reported that vehicles double parked on the road for over $75 \%$ of deliveries. This further confirms research findings where figures between 50 and $86 \%$ were revealed for the share of freight vehicles that park illegally or in situations prone to cause traffic disturbances [18, 20, 32, 33].

Regarding goods characteristics, $65 \%$ of establishments do not have special needs in the handling of their goods. The remaining can label the majority of the goods with one or more of the following descriptors: fragile, perishable and refrigerated. $65 \%$ revealed that goods can have their weight classed as "medium" ( 1 person per unit) and $11 \%$ as "heavy" (more than 1 person per unit or needing auxiliary equipment). Fifty-four percent revealed that their goods can have their volume classed as "medium" (1 person per unit) and $7 \%$ as "big" (more than 1 person per unit or needs auxiliary equipment).

Delivery duration was hypothesized as a pressing concern for establishments as excessive delivery duration, derived from parking in conditions that do not allow easy goods movement, could disrupt business operations for longer than desired. However, the survey results contradict this hypothesis; $97 \%$ of establishments, rated this factor as "indifferent" (39\%) or "adequate" (58\%). This led to a new hypothesis that either: a) delivery duration's effect on business operations is negligible or b) establishments consider the average delivery duration as good as it can be. On the other hand, $50 \%$ of the establishments consider the number and locations of loading/unloading bays, as well as the way loading/unloading operations are performed as either "very inadequate" or "somehow inadequate". This is a non-negligible share of establishments showing dissatisfaction with the present urban freight-supporting infrastructure. Consequently, it is suggested that a policy of reviewing the current parking infrastructure and conditions in which loading/unloading operations are performed should be implemented. 


\subsection{Deliveries per time period and category of establishment}

Total deliveries daily variation, for weekdays, is low. Average daily deliveries per establishment was 8 with a minimum of 3 , maximum of 13 and standard deviation of 4 . Across industry categories, the average weekday deliveries standard deviation (as a percentage of total deliveries) is equal to $9 \%$ with a minimum of $3 \%$, maximum of $19 \%$ and standard deviation of $6 \%$. Having a similar flow of vehicles during weekdays allows an easier planning process of having infrastructure to accommodate parking demand.

On the other hand, there is some variation in average daily arrivals of vehicles, per establishment category and time period (Fig. 3). For example, Food and Drinks establishments have a peak around 8 AM but a comparatively lower number of deliveries in the afternoon period. Health and Hygiene establishments have a peak at 10 AM but a comparatively high number of deliveries around 4 PM, compared to all other categories. This information validates the used category stratification methodology and is relevant for the prediction of delivery arrivals. This allows disaggregating the predictions of total weekly deliveries by assigning them probabilistically, according to the industry category, to a specific 2 -h period, in any given weekday.

\subsection{Correlation analysis}

The correlation analysis compared Establishment Category, Size, Delivery Duration, Quantity of Commodities and Supply Chain characteristics. The most relevant Spearman correlations can be found in Tables 3 and 4 . Table 4 is dedicated to correlations between Supply Chain variables. Relevant correlations were defined as those equal to or higher than 0.4 in absolute values, and significant at $1 \%$ (2-tailed). An exception is given for Table 3, where some correlations are reported regardless of the absolute value or significance, as the conclusions drawn from them are considered of interest to practitioners and have not yet been found in the literature.

In Table 3 it can be seen that there are no high correlations between the total number of weekly deliveries and establishment category or size (commonly employees or sales area) despite the common application of this variables in a context of freight trip generation $[13,14]$. The strongest correlations are for categories 3, 10, and the total of employees. Other variables related to establishment size have also little relevance when considering the total of deliveries such as the size of the warehouse or the frontage width, contrary to what was hypothesized in Cherrett et al. [20].

It is interesting to note the following:

- Increased urgency in receiving deliveries is correlated with a smaller amount of commodities received weekly (commodities were labeled as a unit despite size or weight). Also, increased urgency has the highest average of deliveries (12/week versus 8/week for other answers), but overall, receiving more items is associated with an increased number of deliveries.

- Furthermore, a higher total number of items received per week is barely related to a higher average delivery duration,

We can hypothesize that load consolidation is not a common practice. Otherwise, we would expect receiving more items to be somehow positively correlated with fewer deliveries or higher delivery duration. Hence, it can be said that
Fig. 3 Average daily arrivals of vehicles per establishment category

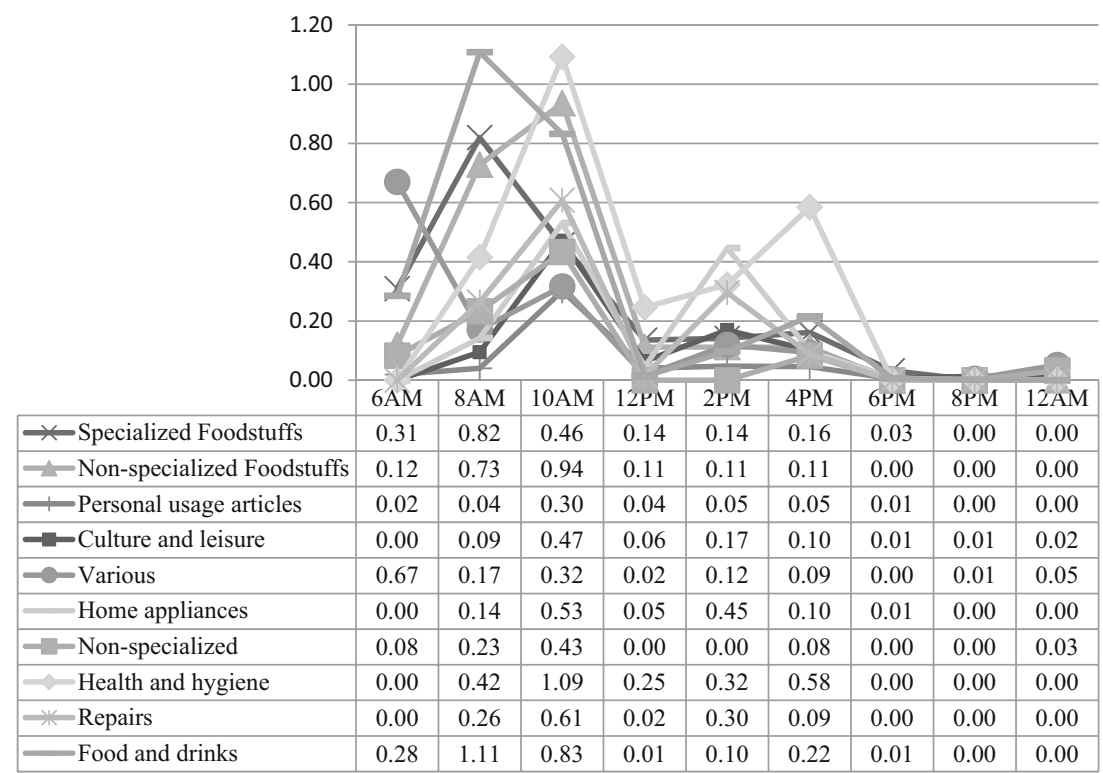


Table 3 Delivery duration, commodities, establishment size and supply chain correlations

\begin{tabular}{|c|c|c|}
\hline Variable 1 & Variable 2 & Correlation (V1 and V2) \\
\hline \multirow[t]{15}{*}{ Total number of Weekly Deliveries } & Category 1 - Specialized foodstuffs & $0.113^{* *}$ \\
\hline & Category 2 - Non-specialized foodstuffs & $0.097 *$ \\
\hline & Category 3 - Personal usage articles & $-0.432 * *$ \\
\hline & Category 4 - Culture and leisure & $-0.197 * *$ \\
\hline & Category 5 - Various & -0.005 \\
\hline & Category 6 - Home appliances & $-0.138 * *$ \\
\hline & Category 7 - Non-specialized & -0.071 \\
\hline & Category $8-$ Health and hygiene & $0.145^{* *}$ \\
\hline & Category 9 - Repairs & -0.025 \\
\hline & Category 10 - Food and drinks & $0.436^{* *}$ \\
\hline & "Sales" area & $0.109 * *$ \\
\hline & Warehouse area & $0.163^{* *}$ \\
\hline & Not having a warehouse & $-0.245^{* *}$ \\
\hline & Frontage width & $0.116^{* *}$ \\
\hline & Employees & $0.449 * *$ \\
\hline \multirow[t]{3}{*}{ Total number of Weekly Deliveries } & Time gap between orders & $-0.671 * *$ \\
\hline & Daily ordering & $0.559 * *$ \\
\hline & Number of Suppliers & $0.404 * *$ \\
\hline Commodity Weight & Commodity Volume & $0.649 * *$ \\
\hline \multirow[t]{7}{*}{ Quantity of Commodities } & Total no. of Weekly deliveries & $0.699 * *$ \\
\hline & Employees & $0.511^{* *}$ \\
\hline & Urgency & $-0.419^{* *}$ \\
\hline & Time gap between orders & $-0.577^{* *}$ \\
\hline & One day between orders & $0.489 * *$ \\
\hline & Origin is "wholesaler"/ is "producer" & $0.483 * * /-0.404 * *$ \\
\hline & Delivery duration & $0.276^{* *}$ \\
\hline Employees & Sales area & $0.422 * *$ \\
\hline
\end{tabular}

** correlations significant at the 0.01 level

*correlations significant at the 0.05 level

there are inefficiencies of order planning or delivery planning that can result in an inflated number of vehicles delivering and subsequently an inflated demand for loading/unloading bays.

In Table 4, many interesting correlations are revealed. Establishments of Category 3 have fewer deliveries per week and bigger time gaps between orders. Establishments of Category 10 place orders based on visual stock inspection and are associated with deliveries by small trucks and with the transport of perishable items. This highlights that industry category labeling also serves the purpose of defining supply chains and targeting those prone to have an inflated number of deliveries due to less-than-optimal business practices or the very nature of the business. In Lisbon, the restaurant business particularly leverages from product differentiation. This business characteristic can be associated with several suppliers for a sametype but somehow different product visiting neighbor establishments (e.g., cheese, bread), which causes an increased number of deliveries.
Daily orders are predominantly related with deliveries arising from the own-company warehouse, which could be associated with establishments taking advantage of having their own fleet. It is unknown if it is related with lower delivery costs. It can also be noticed that, overall, the delivery time/day is defined by the delivery personnel. In practice, this is an incentive for off-hour delivery schemes. If adequate incentives are in place for receivers, suppliers/shippers/carriers have a broader time-frame to perform their deliveries and, assuming they wish to optimize their operations, they would deliver when there is less congestion.

Wholesalers are usually responsible for their own deliveries. 3PL companies are related with deliveries originating from the producer warehouse. 3PLs are also related to refrigerated/perishable items, which are expected with more urgency by establishments. No information was collected regarding the hiring process of 3PLs. Regarding the literature findings in Cherrett et al. [20], no significant relation was found between 
Table 4 Supply chain characteristics correlations

\begin{tabular}{|c|c|c|}
\hline Variable 1 & Variable 2 & Correlation (V1 and V2) \\
\hline Category 3 - Personal usage articles & Time gap between orders & $0.417 * *$ \\
\hline \multirow[t]{6}{*}{ Category $10-$ Food and drinks } & Order based on visual stock inspection & $0.500 * *$ \\
\hline & Order based on computer stock monitoring & $-0.466^{* *}$ \\
\hline & Average time gap between order and delivery & $-0.438 * *$ \\
\hline & Number of small trucks ${ }^{\mathrm{a}}$ delivering & $0.579 * *$ \\
\hline & Average time delivering & $0.552^{* *}$ \\
\hline & Perishable items are majority & $0.537 * *$ \\
\hline (Establishment) Orders daily & Origin is "company warehouse" & $0.426^{* *}$ \\
\hline (Establishment) Several orders $\mathrm{p} /$ week & Hybrid Supply Chain ${ }^{\mathrm{b}}$ & $0.576^{* *}$ \\
\hline (Establishment) Orders once per week & Origin is "company warehouse" & $-0.408 * *$ \\
\hline \multirow[t]{2}{*}{ Establishment-based Fleet } & Own vehicles deliver & $0.534 * *$ \\
\hline & Establishment defines deliveries & $0.419 * *$ \\
\hline \multirow[t]{3}{*}{ Urgency } & Deliveries by $3 \mathrm{PL}$ & $0.454 * *$ \\
\hline & Origin is "wholesaler" / is "producer" & $-0.511 * * / 0.531 * *$ \\
\hline & Average delivery time by light goods vehicle & $-0.448^{* *}$ \\
\hline \multirow[t]{2}{*}{ 3PL delivers } & 3PL / establishment defines delivery time/day & $0.583 * * /-0.485 * *$ \\
\hline & Origin "producer" & $0.488 * *$ \\
\hline Wholesaler delivers & Wholesaler defines delivery time/day & $0.797 * *$ \\
\hline \multirow[t]{5}{*}{ Establishment fleet delivers } & Establishment/3PL defines delivery time/day & $0.652 * * /-0.541 * *$ \\
\hline & Decentralized supply chain ${ }^{c}$ & $-0.405^{* *}$ \\
\hline & Deliveries between unrelated establishments & $-0.463 * *$ \\
\hline & Only deliveries to own establishment & $0.563 * *$ \\
\hline & Origin "company warehouse" & $0.401 * *$ \\
\hline Wholesaler delivers & Origin "wholesaler" & $0.421 * *$ \\
\hline 3PL defines deliveries & Origin "producer" & $0.412 * *$ \\
\hline Establishment defines deliveries & Only deliveries to own establishment & $0.424 * *$ \\
\hline \multirow[t]{4}{*}{ Time gap between orders } & Time gap between order and delivery & $0.546^{* *}$ \\
\hline & Delivering vehicles & $-0.620 * *$ \\
\hline & Total delivery time & $-0.506^{* *}$ \\
\hline & Total delivery time (time gap = 1 day) & $0.495 * *$ \\
\hline Order based on visual stock inspection & Perishable items are majority & $0.409 * *$ \\
\hline Time gap between deliveries & Delivering vehicles & $-0.436^{* *}$ \\
\hline \multirow[t]{3}{*}{ Decentralized Supply Chain } & Deliveries between unrelated establishments & $0.507 * *$ \\
\hline & Only deliveries to own establishment & $-0.414 * *$ \\
\hline & Origin "Company Warehouse" & $-0.507 * *$ \\
\hline \multirow[t]{3}{*}{ Centralized Supply Chain ${ }^{\mathrm{d}}$} & Deliveries between unrelated establishments & $-0.484 * *$ \\
\hline & Only deliveries to own establishment & $0.405^{* *}$ \\
\hline & Origin "Company Warehouse" & $0.544 * *$ \\
\hline Origin "producer" & Refrigerated items are majority & $0.408 * *$ \\
\hline Deliveries with "small truck" & Perishable items are majority & $0.480 * *$ \\
\hline Refrigerated items are majority & Perishable items are majority & $0.606^{* *}$ \\
\hline
\end{tabular}

**correlations significant at 0.01 level; *correlations significant at 0.05 level

a $3.5 \mathrm{~T}<$ Gross Weight $<7.5 \mathrm{~T}$

${ }^{\mathrm{b}}$ Most core goods from centralized supply chain, remaining from decentralized

${ }^{\mathrm{c}}$ Deliveries from multiple suppliers or dispatch points

${ }^{\mathrm{d}}$ Deliveries from single supplier or dispatch point 


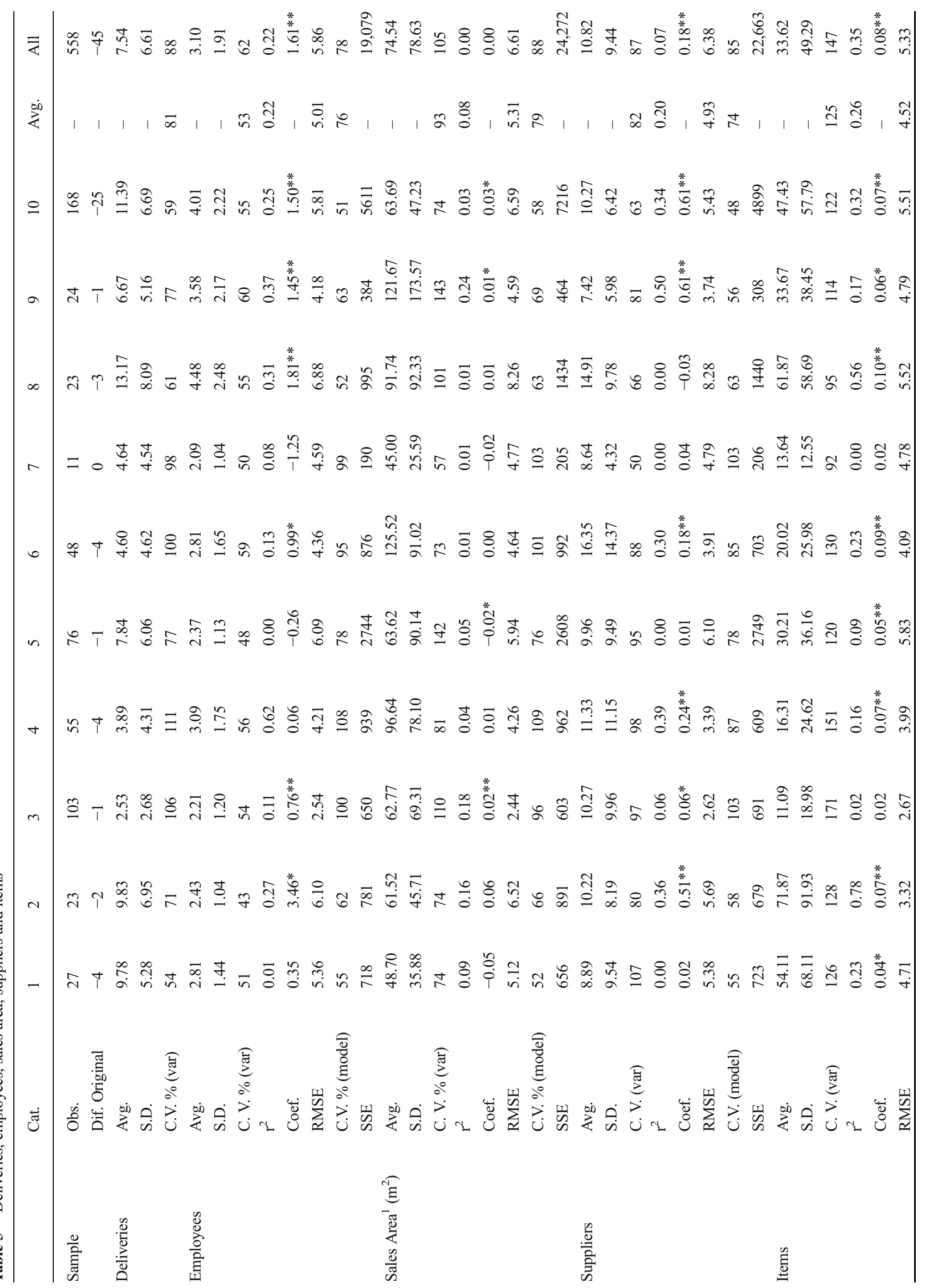


establishments' size or centralized/decentralized supply chains and delivery time

\subsection{Total (weekly) deliveries and Establishment "size" relationships}

In Table 5, we explored the average (Avg.), standard deviation (S.D) and coefficient of variation (C.V., expressed in \%) of the variables: weekly deliveries, employees, sales area, suppliers and items received. In addition, we present regression results between total weekly deliveries and employees, sales area, suppliers or items. Exploring the variable relationships is a crucial step prior to the modeling of freight trip demand which, in turn, allows relating parking demand with existing parking infrastructure to understand if it is adequate. Several indicators are presented to assess the quality of these regressions: $\mathrm{r}^{2}$, coefficients and respective level of significance, root mean squared error (RMSE), coefficient of variation (i.e., relative closeness of the predictions to the actual values, allowing comparing goodness of fit) and sum of squared errors. The novelty of this table lies on the detail of the presentation that will allow future studies to be compared with the results of this case study and, consequently, assess similarities and differences.

Comparing average and standard deviation values, it can be concluded that there is a considerable dispersion of the data for all variables even after the elimination of outliers and influential records. The coefficient of variation confirms this, with no industry category achieving predominantly lower or higher variability across variables. Total employees is the variable with the least average variability, and Items the one with the highest. A model with a smaller CV has predictions closer to the actual values. From this perspective, and considering the models with all categories, contrarily to expected the best predictors of deliveries in due order are items, employees, suppliers, and sales area. This is in line with the models rank considering the lowest Sum of Squared Errors (SSE). The lowest RMSE is present in the models using items or employees as independent variables. Considering $\mathrm{r}^{2}$, the best predictor is the number of items, followed by employees, suppliers and sales area. Still, it must be considered that obtaining information about items or suppliers is not so common as employees or area for the population of establishments.

It must be noted that across categories the $\mathrm{r}^{2}$ varies significantly (e.g., for the independent variable items, between 0.00 and 0.75 ), although this might depend on the variable sample size. In addition, it can be noticed that for each industry category the independent variable that has lower RMSE/SSE may vary (e.g., category 2 versus category 10). Interpreting the regression coefficients, more employees are associated with an increased number of total deliveries, except for categories 5 and 7. The same is true for sales area, except for categories 1,5 

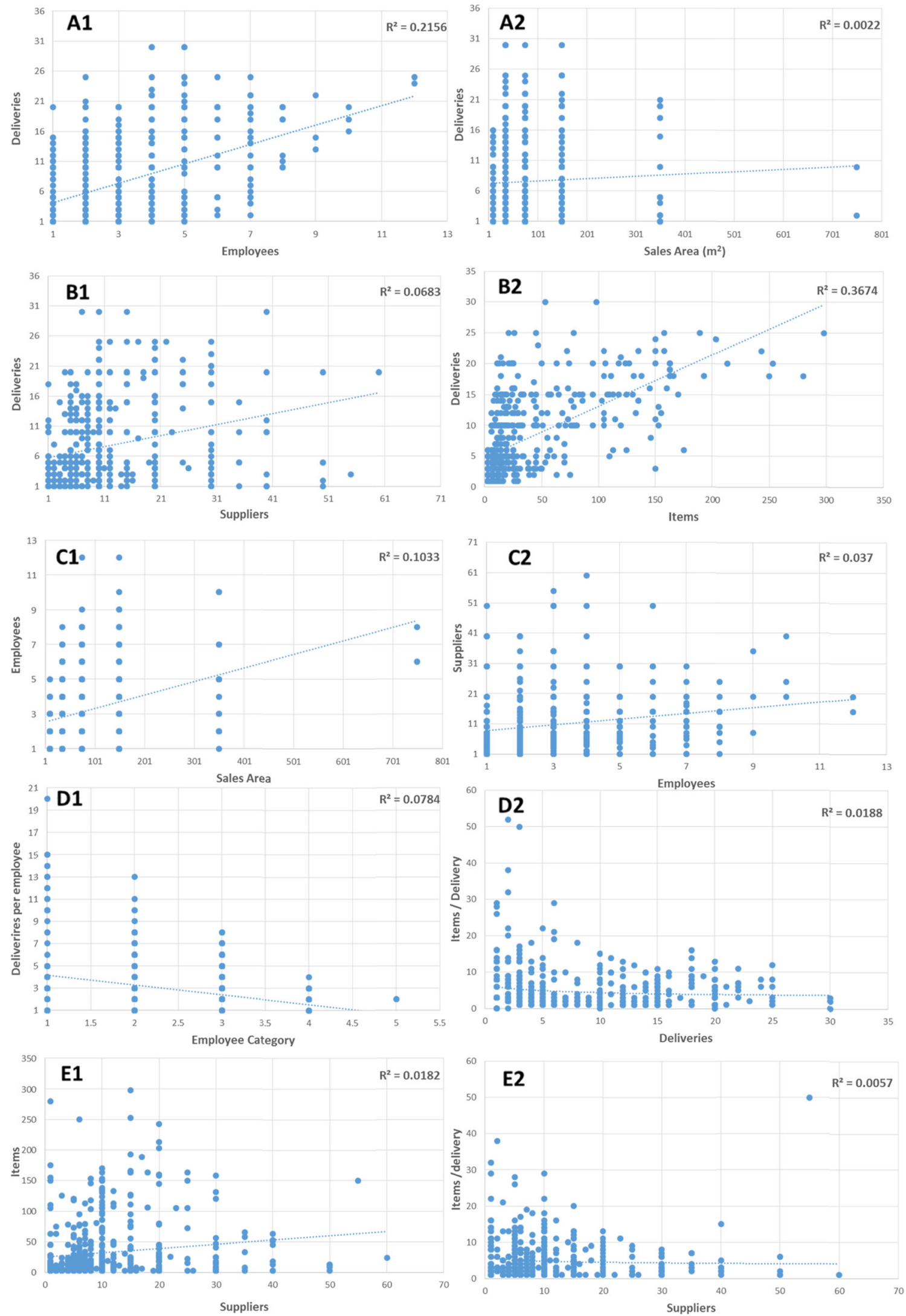

Fig. 4 Scatter plots for deliveries, employees, sales area and suppliers 
and 7. More suppliers and items are also positively related with an increase in deliveries. Nevertheless, it must be stressed that coefficients are small, hinting at weak impacts especially for sales area. Some categories were producing consistently better predictions, regardless of sample size (2, 4, 9 and 10). Despite this, none of the variables seems likely to deliver, under an OLS linear regression framework, adequate forecasts.

A scatter plot analysis in Fig. 4 allows further insights into the data presented in Table 5. In the A1 plot the lower limit of the number of employees increases with the number of deliveries per establishment. On the other hand, sales area shows very feeble relations with the total number of deliveries (A2). The total number of suppliers shows stable lower and upper limit values of suppliers for an increase in deliveries (B1). The lower limit of the number of deliveries increases with the number of items to be delivered (B2). There is a positive relation between the number of employees and sales area (C1). The relation between the number of suppliers and the number of employees is unclear (C2). Categorizing employees as: (1) for 1 employee; (2) for 2 employees; (3) for 3 to 6 employees; (4) for 7 to 10 employees; and (5) for 11 or more employees; more employees are associated with a lower upper limit and average of the total deliveries per employee (D1). In items/delivery vs. delivery scatter plot (D2) only a minority of cases has a comparatively higher number of items per delivery and few deliveries. The relation between items and suppliers (E1) is unclear. The items/delivery vs. suppliers plot (E2) shows, similarly to the items/delivery vs. deliveries plot, only some cases where few suppliers handle a high number of items per delivery, the remaining options are fairly dispersed. Outliers in far right for E1 and E2 plots, when removed, have barely any influence on the trend line.

\section{Conclusions}

It was possible to find a fairly adequate set of guidelines, and even consistent suggestions, to the development and application of EBFS. Despite the scattered nature of the sources, the developed EBFS followed most of the guidelines with success. A set of seven criteria was proposed to help defining the data needs for an EBFS, contextualizing it in the research process. It could be confirmed that EBFS, which require a high investment at various levels, are able to deliver a considerable quantity and variety of data to study urban freight operations. Several novel insights obtained from the data attest to this.

The lack of parking permits for those establishments that are permanently associated with a vehicle demands further research into the vehicle owners' parking practices as these vehicles could be interfering with loading/unloading bay availability. If this is confirmed, stricter parking policies should exist to assure that the infrastructure is able to accommodate some of the demand, avoiding incentives to double parking.

Commerce in Lisbon is predominantly small in size (employees, area) but establishments generate considerable freight movement with an average of 8 deliveries per week. Establishments that sell ready-to-eat food are among the biggest generators and, having declared that they order based on visual inspection, might hint a possibility that some improvements in the ordering process could result in a smaller rate of deliveries. This would certainly have a positive impact on the city as this industry category represents over $30 \%$ of the total establishments.

The challenge of predicting the total of vehicles visiting an establishment for unloading purposes is confirmed by the dynamic nature of the delivery scheduling, the fact that usually who delivers defines the delivery day/h and the weak to moderate relationships between common predictors of the total of trips generated by an establishment (industry, employees, sales area). As predictions might be associated with high errors, special care in dealing with predictions targeting policy analysis is needed.

Scatter plots confirmed that there are only few cases where many items are received in few deliveries, or from few suppliers, hinting that load consolidation requires further research. Future research will also involve further exploration of the variable relationships aiming to propose freight trip generation models with the highest possible predictive capabilities and lowest errors. It would also be of interest to practitioners and policy-makers to promote the development of a comparison platform for EBFS results to assess how variable values compare to other case studies, and on how the conclusions are transferable.

Acknowledgments The authors acknowledge the STRAIGHTSOL Project, co-funded by the European Commission under the Cooperation Work Programme of the Seventh Framework Programme (FP7) for Sustainable Surface Transport, for funding the data collection used in this work.

Open Access This article is distributed under the terms of the Creative Commons Attribution 4.0 International License (http:// creativecommons.org/licenses/by/4.0/), which permits unrestricted use, distribution, and reproduction in any medium, provided you give appropriate credit to the original author(s) and the source, provide a link to the Creative Commons license, and indicate if changes were made.

\section{References}

1. Allen J, Browne M (2008) Review of survey techniques in urban freight studies. Report produced as part of the green logistics project: work module 9 (Urban Freight Transport). University of Westminster, London 
2. Ambrosini C, Patier D, Routhier JL (2010) Urban freight establishment and tour based surveys for policy oriented modeling. Procedia Soc Behav Sci 2(3):6013-6026

3. Ogden K (1992) Urban goods movement: a guide to policy and planning. Ashgate Publishing, United Kingdom

4. Routhier JL, Toilier F (2007) FRETURB V3, a policy oriented software of modeling urban goods movement. Proceedings of the 11th World Conference on Transport Research - WCTR'07, Berkeley, USA

5. Allen J, Anderson S, Browne M, Jones P (2000) A framework for considering policies to encourage sustainable freight traffic and goods/service flows. Summary Report. University of Westminster, London

6. Muñuzuri J, Cortés P, Onieva L, Guadix J (2009) Modeling freight delivery flows: missing link of urban transport analysis. J Urban Plan Dev 135(3):91

7. Allen J, Browne M (2008) Survey forms used in urban freight studies. University of Westminster, London

8. Debauche W (2008) An investigation into the delivery of goods to the city centre of Liege. Belgian Road Research Centre. In: Taniguchi E, Thompson RG (eds) Innovations in City Logistics. Nova Publishers, Belgium, pp 261-276

9. Hunt JD, Stefan K, Brownlee AT (2006) Establishment survey of urban commercial vehicle movements in Alberta, Canada: survey design, implementation, and results. Transp Res Rec: J Transp Res Board 1957:75-83

10. Holguín-Veras J, Patil GR (2008) A multicommodity integrated freight origin-destination synthesis model. J Netw Spatial Econ $8(2-3): 309-326$

11. Muñuzuri J, Cortés P, Guadix J, Onieva L (2010) Modeling peakhour urban freight movements with limited data availability. Comput Ind Eng 59(1):34-44

12. Patier D, Routhier JL (2008) How to improve the capture of urban goods movement data? Reference paper presented at the Session: "Urban goods surveys" 8th International conference on Survey Methods in Transport, Annecy, France

13. Alho A, de Abreu e Silva J (2014) Freight trip generation model: predicting urban freight weekly parking demand from retail establishment characteristics. Transp Res Rec: J Transp Res Board 2411(2):45-54

14. Alho A, de Abreu e Silva J (2015) Modeling commercial establishments' freight demand: a two-step approach to predict weekly deliveries in total of vehicles. Proceedings of the Transportation Research Board 94th Annual Meeting

15. Alho A, de Abreu e Silva J (2015) Utilizing urban form characteristics in urban logistics analysis: a case study in Lisbon, Portugal. J Transp Geogr 42:57-71

16. Danielis R, Rotaris L, Marcucci E (2010) Urban freight policies and distribution channels. Eur Transp 46:114-146

17. Allen J, Browne M, Cherret T, McLeod F (2008) Review of UK urban freight studies. Report produced as part of the Green Logistics Project: Working Module 9, University of Westminster and University of Southampton
18. Delaître L (2009) A new approach to diagnose urban delivery areas plans. Int Conf Comput Ind Eng CIE 6-9:991-998

19. Muñuzuri J, Cortés P, Guadix J, Onieva L (2012) City logistics in Spain: Why it might never work. Cities 29(2):133-141

20. Cherrett T, Allen J, McLeod F, Maynard S, Hickford A, Browne M (2012) Understanding urban freight activity - key issues for freight planning. J Transp Geogr 24:22-32

21. Comendador J, López-Lambas ME, Monzón A (2012) A GPS analysis for urban freight distribution. Procedia Soc Beh Sci 39: 521-533

22. Melo S (2010) Evaluation of urban goods distribution initiatives towards mobility and sustainability: indicators, stakeholders and assessment tools. Doctoral thesis. Faculdade de Engenharia da Universidade do Porto, Portugal

23. Browne M, Allen J (2006) Best practice in data collection, modelling approaches and application fields for urban transport models I. Theme: Urban freight data collection - synthesis report. Best urban Freight Solutions II - EU-FP6 Co-ordination Action

24. Alho A, de Abreu e Silva J, Pinho de Sousa J (2014) A state-of-theart modeling framework to improve congestion by changing the configuration/enforcement of urban logistics loading/unloading bays. Procedia Soc Beh Sci 111(5):360-369

25. CML/DMEI (2009) Número de estabelecimentos de comércio a retalho e restauração da cidade de Lisboa, por sector de actividade económica - 2009. Recenseamento dos estabelecimentos de comércio a retalho e restauração e bebidas da cidade de Lisboa

26. Martínez LM (2010) Financing public transport infrastructure using the value capture concept. Doctoral thesis, Instituto Superior Técnico - Technical University of Lisbon, Portugal

27. Lawson CT, Holguín-Veras J, Sánchez-Díaz I, Jaller M, Campbell S, Powers E (2012) Estimation of freight trip generation based on land use. Transportation Research Board (TRB) 91st Annual Meeting, Washington, DC

28. INE (Instituto Nacional de Estatística). Censos 2011, 2011 http:// censos.ine.pt $/ \mathrm{xportal} / \mathrm{xmain}$ ?xpid $=$ CENSOS\& $\mathrm{xpgid}=$ censos 2011 apresentacao

29. Raosoft (2004) Sample size calculator. Available from: http://www. raosoft.com/samplesize.html. Accessed 25 Jul 2013

30. UCLA: Statistical Consulting Group (2012) Stata Web Books / Regression with Stata / Chapter 2 - Regression Diagnostics. Available from: http://www.ats.ucla.edu/Stat/stata/webbooks/reg/ chapter2/statareg2.htm. Accessed 25 Jul 2013

31. Holguín-Veras J, Wang C, Browne M, Darville Hodge S, Wojtowicz J (2014) The New York city off-hour delivery project: lessons for city logistics. Procedia Soc Beh Sci 125:36-48

32. Aiura N, Taniguchi E (2006) Planning on-street loading-unloading spaces considering the behavior of pickup-delivery vehicles. In: Thompson RG, Taniguchi E (eds) Recent advances in city logistics. Elsevier, Oxford

33. Dezi G, Dondi G, Sangiorgi C (2010) Urban freight transport in bologna: planning commercial vehicle loading/unloading zones. Procedia Soc Beh Sci 2(3):5990-6001 